\title{
The neural circuits of innate fear: detection, integration, action, and memorization
}

\author{
Bianca A. Silva, ${ }^{1}$ Cornelius T. Gross, ${ }^{2}$ and Johannes Gräff ${ }^{1}$ \\ ${ }^{1}$ Laboratory of Neuroepigenetics, Brain Mind Institute, Faculty of Life Sciences, Ecole Polytechnique Fédérale Lausanne, CH-1015 \\ Lausanne, Switzerland; ${ }^{2}$ Mouse Biology Unit, European Molecular Biology Laboratory (EMBL), 00015 Monterotondo, Italy
}

\begin{abstract}
How fear is represented in the brain has generated a lot of research attention, not only because fear increases the chances for survival when appropriately expressed but also because it can lead to anxiety and stress-related disorders when inadequately processed. In this review, we summarize recent progress in the understanding of the neural circuits processing innate fear in rodents. We propose that these circuits are contained within three main functional units in the brain: a detection unit, responsible for gathering sensory information signaling the presence of a threat; an integration unit, responsible for incorporating the various sensory information and recruiting downstream effectors; and an output unit, in charge of initiating appropriate bodily and behavioral responses to the threatful stimulus. In parallel, the experience of innate fear also instructs a learning process leading to the memorization of the fearful event. Interestingly, while the detection, integration, and output units processing acute fear responses to different threats tend to be harbored in distinct brain circuits, memory encoding of these threats seems to rely on a shared learning system.
\end{abstract}

The term "fear" refers to a human emotion characterized by the conscious feeling of being afraid, and as such it is not clear whether a similar emotion also occurs in other species (Panksepp 1989; LeDoux 2012; Anderson and Adolphs 2014). In the field of neuroscience, "fear" is also used to refer to the collective defensive responses elicited by dangers across species and sometimes also to the neural systems that mediate these responses. We favor a more general definition that refers to "fear" as a central state, which is induced when the subject perceives danger and that mediates bodily and behavioral responses to such danger (Adolphs 2013). These responses include defense mechanisms that are necessary for the survival of the individual and can be observed in virtually all animal species. Fear responses are triggered by a variety of stimuli, including predators, aggressive members of the same species, pain, and dangerous features of the environment such as heights. Importantly, these types of stimuli strongly and systematically induce defensive behaviors and do not depend on the experience of direct harm associated with the threat nor on a learning process assigning a valence of danger to the threat. This type of fear is what has been referred to as "innate fear" (Blanchard and Blanchard 1989).

Nevertheless, an innate fear-inducing experience, besides producing an acute adaptive response, also induces the formation of a memory of the fearful event. This is mediated by long-lasting changes in the brain and is aimed to decrease the possibility to reencountering the same threat and to better cope with similar future events. One component of this memory is the association between the innate fear-inducing stimulus and a neutral stimulus such as, for example, the context where it was encountered. This associative form of memory, where a neutral stimulus acquires the ability to induce defensive responses, has been referred to as "conditioned or learned fear" and has for long been the main focus of research attempts to unravel the neural basis of fear (LeDoux 2003, 2014). Accordingly, the brain circuits (for recent reviews, see Herry and Johansen 2014; Tovote et al. 2015), as well as the genetic and molecular underpinnings thereof have been described in great detail (Rodrigues et al. 2004; Johansen et al. 2011) and

Corresponding author: johannes.graeff@epfl.ch

Article is online at http://www.learnmem.org/cgi/doi/10.1101//m.042812.116. Freely available online through the Learning \& Memory Open Access option. will not be repeated here. Importantly, innate and conditioned fear responses seem to be mediated, at least partially, by nonoverlapping circuits (Gross and Canteras 2012), making it impossible to simply transfer our exhaustive understanding of the neural processing of conditioned fear to innate fear.

In this review, we summarize the current knowledge on the brain circuits processing innate fear responses to a wide variety of threats, including predators, aggressive conspecifics and painful stimuli. Accumulating evidence indicates that innate fear to these different types of threats relies on parallel nonoverlapping circuits. Nevertheless, these circuits seem to share a common organization into three fundamental functional levels (Fig. 1): a detection unit composed of different sensory systems, including vision, olfaction, audition, and nociception; an integration unit where the different types of sensory information converge to recruit downstream structures initiating adaptive responses; and an output unit composed of structures directly initiating behavioral and bodily responses. Furthermore, experiencing innate fear can lead to a memorization of the event and thus represents an essential condition for fear learning. In light of this, we also elaborate on the interactions between neural circuits processing innate and learned fear with a particular focus on how innate fear signals instruct fear memorization (Fig. 2).

It is important to note that our current understanding of innate fear circuits largely derives from studies based on predator fear, as other classes of threat, including aggressive conspecifics or physically harmful threats, have been less studied. Here, we attempt to comprehensively summarize the neural circuits recruited by exposure to all kinds of threat, bearing in mind that certain aspects can only be addressed in light of predator fear research.

\section{Detection unit}

Although threats vary for different species, here we will focus on rodents as they are the most commonly used model organisms for the study of fear circuits.

(C) 2016 Silva et al. This article, published in Learning \& Memory, is available under a Creative Commons License (Attribution 4.0 International), as described at http://creativecommons.org/licenses/by/4.0/. 


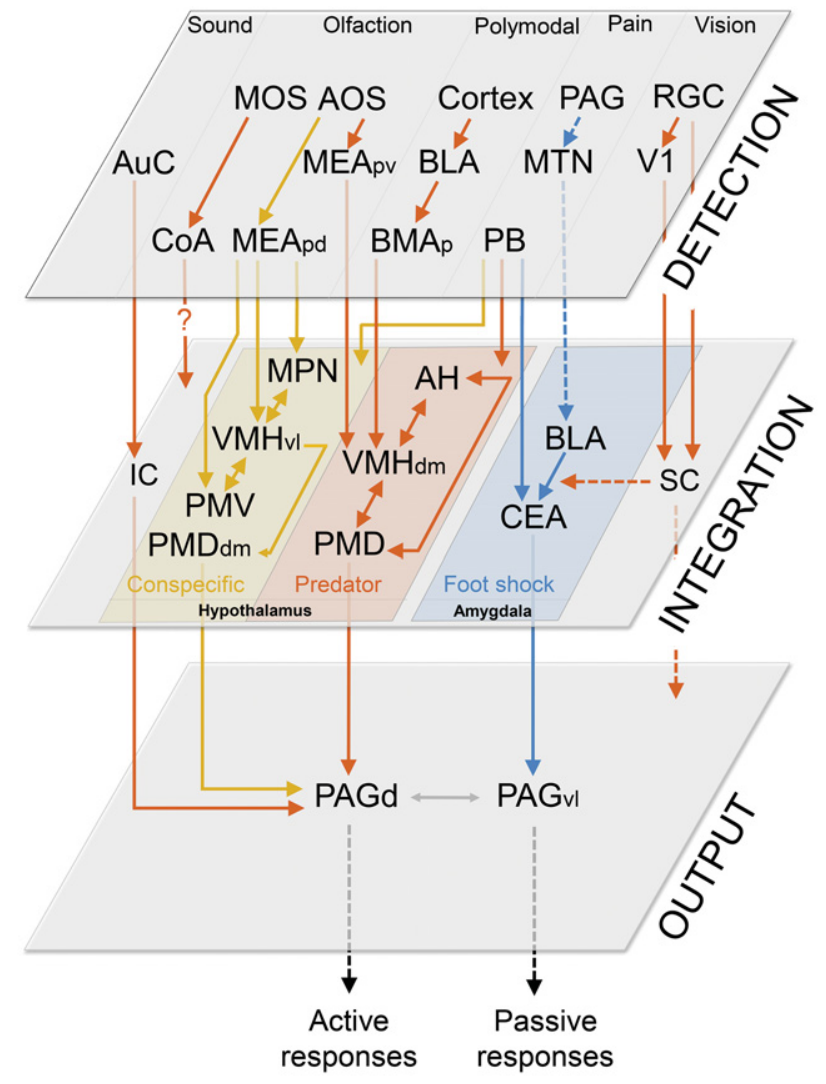

Figure 1. Schematic representation of the neural circuits mediating innate fear to different threats. Three main functional units process innate fear, a detection unit (upper plane), an integration unit (middle plane), and an output unit (lower plane). Information about the threat is collected through different sensory modalities. Acoustic inputs (such as ultrasounds) are processed by the auditory cortex (AuC), which in turn projects to the inferior colliculus (IC) that sends afferents to the dorsal periaqueductal gray (PAGd). Moving visual stimuli in the upper visual field are processed by the superior colliculus (SC), which receives inputs from the retinal ganglion cells (RGN) and primary visual cortex (V1) and mediates fear responses through targeting the amygdala and brainstem. Olfaction plays a crucial role in the detection of both predator (orange) and conspecific (yellow) signals. The main olfactory system (MOS) mediates defensive responses to the predator odor via projections to the cortical amygdala ( $\mathrm{CoA})$, but the outputs of this structure mediating behavioral responses remain unclear. The accessory olfactory system (AOS) signals conspecific cues to the posterior dorsal portion of the medial amygdala (MEAdd) and predator cues to its posterior ventral portion (MEApv). These two medial amygdalar nuclei project to the conspecific and predator integration circuits in the hypothalamus. The predator fear circuit also receives polymodal sensory information about the threat via a basolateral amygdala (BLA)-basomedial amygdala (BMA) circuit. The hypothalamic integration unit processing conspecific fear includes four highly interconnected nuclei: the medial preoptic nucleus (MPN), the ventrolateral portion of the ventromedial hypothalamic nucleus (VMHvl), ventral premammillary nucleus (PMV), and dorsomedial portion of the dorsal premammillary nucleus (PMDdm). The conspecific fear circuit mediates defensive responses through its projections to the PAGd. The predator fear circuit consists of the anterior hypothalamic nucleus (AH), the VMHdm, and the PMD and mediates defensive responses through projections to the PAGd. Importantly, both the conspecific and predator hypothalamic circuits receive nociceptive information from the parabrachial nucleus (PB). Defense to painful stimuli (blue lines) such as an electrical footshock is mediated by activation of the ventrolateral periaqueductal gray (VIPAG) via the central nucleus of the amygdala (CEA). The CEA receives noxious information from the parabrachial nucleus (PB). The basolateral amygdala complex (BLA) plays a major role in footshock-induced fear through its projections to the CEA. The BLA integrates nociceptive information from the PAG via midline thalamic nuclei (MTN).
Three main classes of threats inducing innate fear in rodents exist: predators, aggressive members of the same species, and internal information such as painful stimuli or suffocation signals. All these types of threats are detected by the brain via different sensory modalities, including olfaction, vision, audition, and nociception. Interestingly, many examples show that signals from a single sensory modality such as predator odor, a moving shadow from above, or ultrasound calls are independently sufficient to drive acute defensive responses.

\section{Olfactory threat cues}

In contrast to humans, rodents mainly rely on their sense of smell to collect information about the environment. Most olfactory signals have the capability to instruct behavior through experiential association, yet a subset of odorants innately drives defensive responses (Stowers and Kuo 2015). These include odorants from bodily secretions like urine, feces, or saliva from predators including felines, rats, snakes, and predatory birds (Isogai et al. 2011), as well as odors from stressed conspecifics (Brechbühl et al. 2008; Stowers and Logan 2010; Rosen et al. 2015). A number of predatorderived single molecules capable of inducing innate fear have been identified, which include urinary protein homologues from cat fur (Papes et al. 2010), 2-phenylethylamine from the urine of carnivores (Ferrero et al. 2011), and 2,4,5-trimethylthiazoline (TMT) from fox feces (Rosen et al. 2015).

The detection of odorants signaling danger relies on two main systems: the main olfactory system (MOS) and the accessory olfactory system (AOS). The MOS is capable of sensing an extremely wide range of volatile molecules conveying information about the environment, whereas the AOS appears to serve a more specialized function for the detection of odorants from other individuals. In particular, the AOS senses pheromones (Dulac and Torello 2003), which signal intraspecific information and kairomones-that is, odorants derived from nonconspecific individuals such as predators (Ben-Shaul et al. 2010; Papes et al. 2010). Additionally, a third olfactory organ located in the nasal cavity, the Grueneberg ganglion cells system, relays olfactory signals of danger mainly derived from injured conspecifics (Brechbühl et al. 2008). Interestingly, all these olfactory systems can directly instruct fear responses to different predator odorants recruiting partially divergent downstream brain circuits (Takahashi 2014; Pérez-Gómez et al. 2015).

The MOS detects volatile odorants through sensory neurons of the olfactory epithelium that project to specific structures in the main olfactory bulb (MOB) called glomeruli, whereas the AOS detects fluid-phase chemicals through the vomeronasal organ (VNO), a chemoreceptive structure located at the base of the nasal septum that projects to the accessory olfactory bulb (AOB Meredith 1991; Breer et al. 2006; Isogai et al. 2011). Detailed insight into the function of the MOS in the innate fear circuit is derived from studies using the fox feces-derived molecule TMT as a predator signal (for a review, see Rosen et al. 2015). TMT is detected by nasal epithelium neurons projecting to mitral cells in the posterior dorsal olfactory bulb (Kobayakawa et al. 2007; Matsumoto et al. 2010), which, in turn, project to the anterior cortical amygdala (CoA, Miyamichi et al. 2011), a structure driving defensive behaviors (Root et al. 2014). Accordingly, optogenetic inhibition of the CoA reduces TMT-induced defensive behavior, whereas selective activation of TMT-responsive CoA neurons is sufficient to recapitulate TMT-induced fear behaviors (Root et al. 2014). However, the target structures of CoA neurons mediating defensive responses have not been identified. Yang et al. (2016) recently described a putative circuit processing TMT signals, where glutamatergic projections from the lateral habenula activate parvalbumin-positive $(\mathrm{PV}+)$ interneurons in 
the laterodorsal tegmentum, which in turn drive fear responses including freezing, accelerated heart rate, and increased serum corticosterone levels. Other areas may also contribute to the processing TMT-induced fear such as the bed nucleus of the stria terminalis (BNST; Fendt et al. 2003), the lateral septum (LS; Endres and Fendt 2008), and the central amydgala (CEA; Isosaka et al. 2015), as their inactivation reduces TMT-inducer fear behaviors. Lastly, a recent paper showed a specific area of the olfactory cortex, the amygdalo piriform transition area, to mediate stress hormone responses to predator odors (Kondoh et al. 2016). Yet, a comprehensive understanding of the interplay between the pathways processing TMT-induced fear responses remains to be determined.

Differently from the MOS, the AOS relies on a separate set of brain structures to convey threat signals. In particular, the AOB, which processes vomeronasal inputs, sends projections to the medial amygdala (MEA), a structure-mediating innate predator and conspecific fear (Motta et al. 2009) as evidenced by c-Fos mapping and lesion studies (Li et al. 2004; Blanchard et al. 2005; Motta et al. 2009). The MEA, in turn, serves as a major input to the medial hypothalamic defensive system (for detailed description see "integration unit") that integrates olfactory and nonolfactory stimuli and recruits downstream structures like the dorsal PAG (PAGd) for the initiation of defensive behaviors (Canteras 2002).

The olfactory threat detection unit mainly serves the innate fear system to sense the presence of predators. Nevertheless, fear responses are also elicited by exposure to aggressive conspecifics and olfaction seems to play an important role to signal social threats. For example, the VNO is recruited by exposure to a number of intraspecific signals including androgens (Isogai et al. 2011) found in the sweat of males of most mammalian species
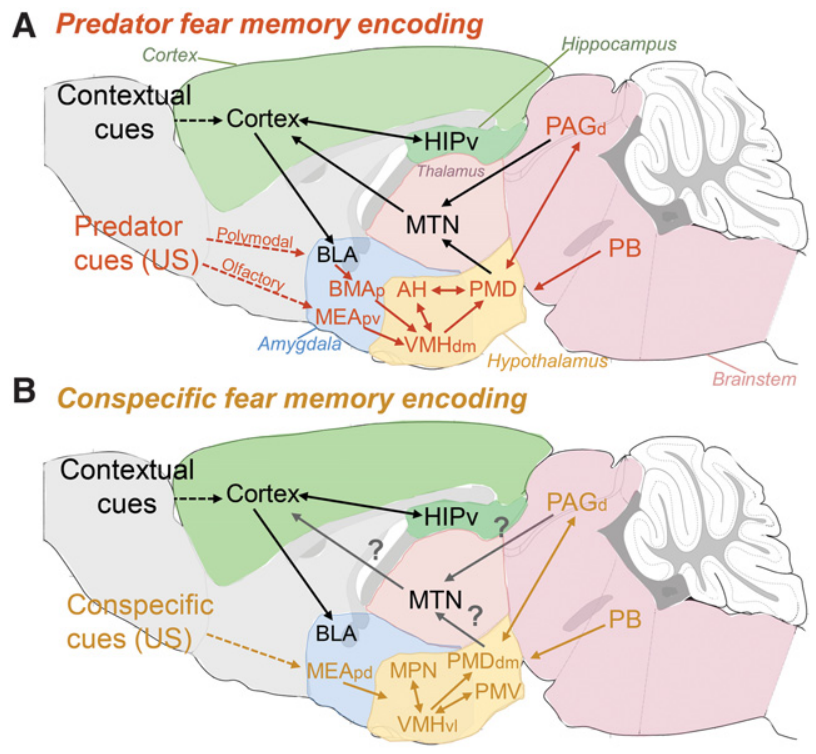

\section{Foot shock fear memory encoding}

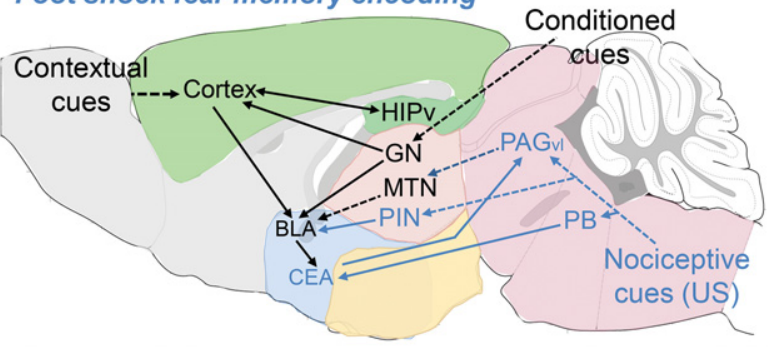

and able to induce elevated stress hormones and stress-mediated analgesia in mice (Sorge et al. 2014). In addition, odorants from stressed or injured conspecifics can also signal danger. Interestingly, these signals are detected by the Grueneberg ganglion cells system (Brechbühl et al. 2008). Grueneberg ganglion neurons are located in the anterior region of the nasal cavity and project to the MOB, but the downstream structures recruited by these neurons in the modulation of defensive responses have not been identified.

\section{Visual threat cues}

Mice and rats display defensive responses including flight, shelter seeking, and freezing to looming shadows in the upper visual field (Wallace et al. 2013; Yilmaz and Meister 2013). In the laboratory, these responses have been mimicked by displaying an expanding

Figure 2. Hypothetical circuits mediating memorization of fear to different classes of threats. Innate fear circuits for all classes of threats interact with a common memorization unit centered in the amygdala, hippocampus, and cortex (black lines). (A) Memorization of predator fear. Information about the predator (US inputs: orange lines) are conveyed to the hypothalamus through the amygdala with the MEApv processing olfactory information and the posterior portion of the basomedial amygdala (BMAp) processing cortical polymodal information conveyed through the basolateral amygdala (BLA). In addition, the MHDS receives afferents from the parabrachial nucleus (PB), which probably conveys pain signals that may emerge during the encounter with a predator. The medial hypothalamic defensive system (MHDS), composed of the anterior nucleus $(\mathrm{AH})$, the dorsomedial portion of the ventromedial hypothalamus (VMHdm), and the dorsal premammillary nucleus (PMD), integrates sensory-derived information and drives acute defensive responses through its downstream projections to the dorsal portion of the priaqueductal gray (PAGd). The MHDS and the PAGd send upstream projections to midline thalamic nuclei (MTN), including the anteromedial thalamic nucleus which, in turn, projects to cortical structures including the anterior cingulate, retrosplenial, entorhinal, and perirhinal cortices, areas implicated in contextual fear learning. These upstream projections from hypothalamic and PAG innate fear circuit may convey US signals to the memorization unit involving cortical, amygdalar, and hippocampal structures. The precise processing of CS-US integration remains unclear. (B) Memorization of conspecific fear. This circuit has not been fully investigated; as a result, this part of the model is highly speculative. Information about the aggressive conspecific (US inputs: yellow lines) is conveyed to the hypothalamus through the MEApd. The hypothalamic circuit involving the medial preoptic nucleus (MPO), the ventrolateral portion of the ventromedial hypothalamus (VMHvl), the ventral premammillary nucleus (PMV) and the dorsomedial portion of the dorsal premammillary nucleus (PMDdm) integrate conspecific signals and drive acute defensive responses through its downstream projections to the PAGd. Similarly to the predator system PB inputs to these hypothalamic nuclei might convey nociceptive information that emerge in the case of attacks by an aggressive conspecific. It is possible that the conspecific innate fear circuit sends upstream projection to midline thalamic nuclei and thereby instructs memory formation similarly to the predator fear circuit. However, this has not been directly addressed. (C) Memorization of footshock fear. Contextual information (CS) are conveyed through cortico-thalamic inputs to the basolateral amygdalar complex (BLA) and ventral hippocampus (HIPv), while other conditioned cues such as auditory inputs are conveyed to the BLA and cortex through sensory thalamic nuclei such as the geniculate nuclei (GN). How nociceptive information (US inputs: blue lines) reaches the cortico-amygdalohippocampal memorization system is less clear. A spino-thalamic tract may convey nociceptive inputs to the BLA and to other cortical structures through the posterior intralaminar thalamic nuclei (PIN). However, ibotenic lesions at this level do not impair fear learning. Another possible source of nociceptive inputs may arise from the ventrolateral periaquiductal grey (PAGvl) targeting the BLA through MTN relay stations. Moreover, the brainstem parabrachial nucleus (PB) directly conveys nociceptive inputs to the central amygdala (CEA), which, in turn, mediates defensive behaviors via its projections to the PAGvl. The implicated brain structures have been indicated at their approximate positions so as to still keep the legend readable and are colored for ease of reading. 
dark circle or a moving bar on a screen positioned on top of the animal's cage and are likely to reflect natural responses to approaching birds of prey. Indeed, vision is the only effective way to detect these types of threat. Interestingly, laboratory mice seem to show higher freezing when exposed to an overhead looming stimulus than to a predator odor (Apfelbach et al. 2005; Yilmaz and Meister 2013), which might reflect an adaptation of rodents to prevent strictly visually guided aerial predators from detecting them (Yilmaz and Meister 2013).

Despite the robustness of looming stimuli-evoked defensive behaviors, we still know very little about the neural processing underlying such responses. The very short latency of defensive responses to looming stimuli (down to $250 \mathrm{msec}$; Ylimaz and Meister 2013) suggests a limited amount of central processing and possible direct visual inputs to brainstem defense systems, at least for the immediate freezing and escape responses. Different lines of experimental evidence suggest the SC as a major regulator of visual stimuli-induced defensive behaviors. SC is activated by overhead shadows (Zhao et al. 2014; Shang et al. 2015), its electrical and chemical stimulation induce defensive behaviors (Sahibzada et al. 1986; Dean et al. 1988; Keay et al. 1988; Schenberg et al. 1990; Sudré et al. 1993), and SC lesions impair defensive reactions to an approaching experimenter and to a sudden overhead visual stimulus (Dean et al. 1989).

Several circuits centered in the SC have been proposed for the processing of looming stimuli-induced defensive responses. For instance, using optrode recordings and optogenetic manipulations, Shang et al. (2015) identified a retino-SC-parabigeminal nucleus circuit with PV+ excitatory projection neurons located in the SC serving as a sensory-motor processor of looming-induced stimuli. In contrast, Liang et al. (2015) showed that V1 layer 5 neurons projecting to the SC can directly influence defensive behavior to a visual stimulus, thus suggesting an alternative circuit for SC recruitment upon visual stimuli exposure (Liang et al. 2015). Yet another route of visual detection was identified by Wei et al. (2015) who showed that CaMKII positive cells in the SC responding to looming stimuli mediate defensive behaviors by recruiting the lateral amygdala (LA) via the lateral posterior nucleus of the thalamus. The precise hierarchical interactions between these circuits and their reciprocal connections are currently under investigation. One possible explanation of these apparently redundant circuits is that the retino-PV $+\mathrm{SC}$-brainstem circuit mediates active escape responses associated with increased heart rate (Shang et al. 2015), whereas the CaMKII+ SC-lateral posterior thalamus-LA circuits mediates passive responses like freezing associated with bradycardia (Wei et al. 2015), likely via a CEA-ventrolateral periaqueductal gray (PAGvl) output circuit (see below).

\section{Auditory threat cues}

Mammals frequently depend on their sense of hearing to detect threats, particularly in nocturnal species. As a result, auditory cues have widely been used to elicit defensive responses in associative learning paradigms where animals learn to associate an electrical footshock with a neutral sound. The neural circuits underlying such tone-induced conditioned fear responses have been investigated in considerable depth (Herry and Johansen 2014; Tovote et al. 2015). However, under certain conditions, auditory stimuli can themselves induce innate fear responses. For instance, $17-22 \mathrm{kHz}$ ultrasound tones can induce flight and freezing responses in mice (Mongeau et al. 2003) probably recruiting a specialized threat-detection system, given that ultrasonic vocalizations serve as alarm cries in rats exposed to predator odor (Blanchard et al. 1991; Litvin et al. 2007). Only a few studies have investigated the neural circuits of sound-induced innate fear. Mongeau et al. (2003) showed that mice exposed to ultrasonic tones in their home cages show increased c-Fos expression in the inferior colliculus (IC) region responsive to $17-20 \mathrm{kHz}$ sounds, and in the dorsal PAG. In line with these findings, Xiong et al. (2015) used pharmacological and optogenetic manipulations to identify an auditory cortex-IC-PAGd circuit mediating flight responses to 1-64 kHz loud noise. Yet, other circuits are likely to be identified in future studies.

\section{Noxious stimuli}

Acute fear responses to pure noxious stimuli have not been investigated in depth and it is currently not clear whether these stimuli are indeed sufficient to induce innate fear responses (Box 1). In contrast, painful stimuli like an electrical foot shock have widely been used in the study of conditioned fear where animals learn to associate the noxious aversive stimulus with neutral cues or contexts (for recent reviews, see Herry and Johansen 2014; Tovote et al. 2015) and subsequently express fear responses to those.

The neural circuits at the basis of this type of emotional learning are centered in the basolateral amygdalar complex (BLA) and have been studied in great detail (Box 1). Yet, how nociceptive signals are detected by the BLA learning system is still unclear. Some studies suggest that the sensory discriminative component of the nociceptive information is conveyed to the BLA via a spino-thalamic tract composed of lamina I spinal cord neurons targeting the posterior intralaminar thalamic nucleus (PIN), which in turn sends excitatory projections to the BLA (Asede et al. 2015; Bienvenu et al. 2015). However, this hypothesis has been challenged by studies showing that fiber-sparing lesions in this area do not impair footshock learning (Brunzell and Kim 2001; Lanuza et al. 2008; Herry and Johansen 2014). An alternative input carrying nociceptive information to the BLA might originate from the PAG through midline thalamic or other cortical relays, because the PAG integrates nociceptive inputs from the spinal and trigeminal dorsal horn (Johansen et al. 2010) and PAG electrical stimulation is sufficient to instruct BLA-dependent fear learning (Di Scala et al. 1987; Kim et al. 2013). Similarly, pharmacological inhibition of PAG during fear conditioning impairs footshock-induced fear memory encoding (Johansen et al. 2010).

Furthermore, nociceptive information is also directly detected by the CEA, a structure serving as the main output of BLAmediated conditioned fear responses (Box 1). This amygdalar sub-region receives nociceptive signals from the parabrachial nucleus (PB, Bernard and Besson 1990), responds to nociceptive stimuli (Neugebauer and Li 2002) and its inactivation impairs fear learning (Wilensky et al. 2006). Moreover, recent studies have nicely identified a putative circuit mediating CS-US associative learning centered in the CEA, composed of spinoparabrachial afferents conveying the affective component of nociceptive information to the CEA (Han et al. 2015; Sato et al. 2015; Sugimura et al. 2016). Taken together this evidence suggests that both the BLA complex and the CEA contribute to footshock fear memory encoding; however, the interplay within these two structures in the processing of footshock fear learning remains poorly understood.

\section{Suffocation signals}

The neural circuits of fear induced by suffocation signals have attracted particular attention for their relevance to panic disorder, where hyper-responsivity of this system has been proposed to represent a major contributor to this pathology (Klein 1993; Preter and Klein 2008; 2014). Obstructions to respiration invoke intense innate responses across animal species (Schimitel et al. 2012). The brain is thought to detect suffocation through sensors of blood $\mathrm{O}_{2}$ and $\mathrm{CO}_{2}$ partial pressure located in the carotid body (Finley and Katz 1992). Hypoxia (low $\mathrm{O}_{2}$ ) or hypercapnia $\left(\right.$ high $\left.\mathrm{CO}_{2}\right)$ signals 
BOX 1. Footshock-associated pain as informative threat stimulus supporting fear learning

Despite being the most widely used stimulus to study fear learning, whether a nociceptive event per se induces innate fear is controversial. Typically, innate fear responses to natural threats allow animals to avoid harm without having to experience it (Blanchard and Blanchard 1988). Pain, on the other hand, is a more universal signal of harm that presumably developed to help animals avoid stimuli that are not registered by their innate fear systems. If this is true, then pain (despite being innately aversive) should not induce innate fear, but instead should act as an informative unconditioned stimulus (US) to drive conditioned responses (CR) associated with the pain context or cue (which serves as the conditioned stimulus, or CS). Evidence for this interpretation can be found in the immediate shock deficit. Several experiments have shown that rodents do not show defensive behaviors like freezing, passive avoidance, or potentiated startle when the shock is delivered in a novel context without delay. This, in turn, suggests that defensive responses observed when rodents receive a shock after they have been exposed to a context for a certain time frame are most likely conditioned responses to such context and not innate responses to the footshock (Bolles and Fanselow 1980; Fanselow 1990; Kiernan et al. 1995; Landeira-Fernandez et al. 2006).

The neural processes underlying this form of emotional learning — and behavioral tests to elicit this response-are by far the most widely used to study conditioned fear, and the circuits governing the encoding, retrieval, and extinction of such responses are consequently well described (for recent reviews, see Herry and Johansen 2014; Tovote et al. 2015). In brief, this foot-shock US-CS associative fear learning system is centered in the basolateral amygdalar complex (BLA), which integrates unconditioned and conditioned signals and harbors plasticity mechanisms that form the basis of fear memory encoding. In particular, CS information is directly targeted to the BLA complex through auditory and somatosensory thalamic and cortical inputs, whereas US signals to the BLA may arise from indirect inputs from the PAG or other cortical areas (Fig. 2; Johansen et al. 2010, Herry and Johansen 2014). The BLA complex then projects to the CEA, a structure necessary and sufficient for the initiation of various defensive responses via projections to multiple downstream targets (LeDoux 2003), including the vIPAG, which mediates freezing and behavioral inhibition (LeDoux et al. 1988), and the substantia innominata, which mediates arousal, attention, and active behaviors (Gozzi et al. 2010). In addition, the CEA projects to the lateral and dorsal hypothalamus facilitating the hypothalamus-pituitary-adrenal gland (HPA) axis activation (LeDoux 2003; LeDoux et al. 1988) and to the dorsal motor nucleus of the vagus nerve and parabrachial nucleus (Bandler and Shipley 1994; Hopkins and Holstege 1978) mediating parasympathetic autonomic responses.

Importantly, a growing body of evidence indicates that the CEA not only serves as a output structure of the BLA, but also harbors plasticity mechanisms necessary for fear learning itself (Keifer et al. 2015; Wilensky et al. 2006; Sato et al. 2015; Ciocchi et al. 2010; Duvarci et al. 2011). In particular, a recent study has shown that the CEA directly integrates US nociceptive signals from the parabrachial nucleus and CS stimuli deriving from the auditory thalamus via the LA (Han et al. 2015).

from the carotid are processed by the nucleus of the solitary tract (NTS) that, in turn, targets respiration nuclei in the medulla for respiratory adaptations (Loewy and Burton 1978; Paton et al. 2001), as well as higher structures involved in the generation of defensive responses such as PAG, CEA, and the paraventricular nucleus of the hypothalamus (Ricardo and Tongju Koh 1978). Indeed, severe hypoxia induces significant increases in c-Fos protein expression in the NTS and in the dorsolateral and lateral columns of the PAG (Casanova et al. 2013), and lesions in the PAG suppress hypoxia-induced defensive behaviors (Schimitel et al. 2012). Moreover, slice electrophysiology experiments have shown that the PAGd harbors hypoxia-responding neurons (Kramer et al. 1999). Taken together, these findings indicate that the dorsal PAG may serve as a central node in the processing of hypoxiainduced fear (Schenberg et al. 2014).

\section{Integration unit}

Once the brain detects a threat, the associated information is conveyed from primary sensory structures to downstream structures. There, all the sensory information coming from the threat, the environment, and the subject's internal state are integrated to recruit-in an orchestrated manner-the downstream effectors initiating the most appropriate motor and homeostatic responses. The brain circuits occupying such an intermediate position in the sensory-motor processing of fear responses constitute what we define here as an "integration functional unit." Originally, it has been hypothesized that this fear integration circuit consists of a unique set of nuclei centered in the amygdala that processes signals from all types of threats to give rise to a stereotyped set of defensive responses (Bolles and Fanselow 1980; Fanselow 1994). However, this view has been challenged by a number of subsequent studies, indicating that the brain processing of innate fear occurs in separate circuits depending on the type of threat. Such high degree of functional segregation is not only observable at the level of the detection unit, but also of downstream integration functional elements.

In particular, in contrast to the amygdala-centered footshock fear circuit, conspecific and predator fear are primarily integrated by parallel circuits located in the medial hypothalamus (Fig 1; Gross and Canteras 2012; Silva et al. 2013). These hypothalamic circuits, despite being ethologically relevant, have received less attention compared to the deeply investigated amygdalar fear circuits. In the following section we summarize the organization of the functional integration unit processing predator, conspecific and footshock fear, with a particular focus on recent studies highlighting the hypothalamic function in fear integration.

\section{The predator fear circuit}

In rodents the core integration unit for fear to predatory threats resides in the medial hypothalamic defensive system (MHDS; Canteras 2002). This system consists of a set of nuclei located in the hypothalamic medial zone: the anterior hypothalamic nucleus $(\mathrm{AH})$, the dorsomedial portion of the ventromedial hypothalamus (VMHdm), and the dorsal premammillary nucleus (PMD). These three highly interconnected nuclei are selectively recruited by predator exposure (and not by conspecific threat or pain), receive inputs from sensory circuits detecting predatory cues, and target defense output structures like the PAG (Canteras 2002). Accordingly, inhibition of these nuclei impairs defensive responses to predators while their artificial activation promotes defensive responses in both rodents and primates (Lipp and Hunsperger 1978; Canteras et al. 1997; Blanchard et al. 2005; Wilent et al. 2010; Pavesi et al. 2011; Silva et al. 2013; Kunwar et al. 2015; Wang et al. 2015).

The functional anatomy of the medial hypothalamic defensive circuit mediating predator fear has been described in detail (for reviews, see Canteras 2002; Gross and Canteras 2012). It receives massive inputs from sensory structures of the detection units through two amygdalar regions: the medial nucleus (MEA), 
which conveys olfactory information from the vomeronasal organ; and the basomedial nucleus (BMA), which conveys wider polymodal information about the predatory threat through its BLA inputs, which in turn receives information from olfactory, insular, and prefrontal cortices. Importantly, parallel amygdalar inputs are also relayed to the MHDS by the interfascicular nucleus of the bed nucleus of the stria terminalis, a structure implicated in aversion processing (Walker et al. 2003). In addition, the MHDS is also targeted by the hippocampal-septal system, conveying processed sensory information including spatial and novelty signals (Canteras 2002). Although never directly tested, information conveyed by these inputs may be important to best adapt the behavioral output strategy to contextual features such as availability of an escape route and proximity of the threat. In addition, the MHDS also receives afferents from the parabrachial nucleus (Bester et al. 1997), a structure detecting the bodily internal state, and from the medial prefrontal cortex, probably exerting a topdown control on defensive responses (Comoli et al. 2000).

The major outputs of the MHDS target motor output initiators such as the PAGd and SC and thereby mediate behavioral defensive responses to predators. In addition, the MHDS also regulates autonomic and endocrine functions through efferents to the dorsomedial hypothalamic nucleus, the vagal motor nerve, and the paraventricular hypothalamic nucleus (Canteras 2002).

All this evidence indicates the fundamental role of the MHDS in integrating signals from the predatory threat detection unit and in orchestrating responses targeting the output unit. Nevertheless, it is important to note that even if the MHDS plays a central role in integrating predator fear, anti-predator defense can, in some specific cases, rely on alternative circuits bypassing the hypothalamus (Kunwar et al. 2015). For instance, rapid responses to looming stimuli seem to rely on more direct inputs to PAG from SC (Zhao et al. 2014; Shang et al. 2015) and ultrasound-induce defensive responses may rely mainly on circuits centered in the IC (Xiong et al. 2015). What is more, recent studies have argued that the MHDS is not only involved in the sensorymotor processing of defensive responses but, at the same time, also actively serves to encode a generalized internal motivational state of fear that may reflect the emotion associated with threat exposure (see below; Kunwar et al. 2015; Silva et al. 2016). Interestingly, some studies showed that electrical stimulations of the $\mathrm{VMH}$, a nucleus of the MHDS, in humans elicited panic attacks (Wilent et al 2010), pointing to a possible conservation of this predator fear integrator also in humans.

\section{The conspecific fear circuit}

Surprisingly, rodents show escape and defensive responses to an aggressive conspecific display activation of a set of brain structures that do not overlap with the ones recruited by exposure to a predatory threat or a physically harmful stimulus (Motta et al. 2009; Silva et al. 2013). The core integration unit processing conspecific fear overlaps with the medial hypothalamic reproductive system known to be recruited during sexual and aggressive behavior. This set of nuclei includes the medial preoptic nucleus $(\mathrm{MPN})$, ventrolateral portion of the ventromedial hypothalamus (VMHvl), the ventral premammillary nucleus (PMV) and dorsomedial portion of the dorsal premammillary nucleus (PMDdm) (Kollack-Walker and Newman 1995; Kollack-Walker et al. 1999; Motta et al. 2009; Lin et al. 2011; Yang et al. 2013). Accordingly, pharmacogenetic inhibition of the VMHvl (Silva et al. 2013) or lesions of the PMDdm decreases defensive responses to an aggressive conspecific (Motta et al. 2009), indicating that this hypothalamic system is necessary to process social fear. Importantly, selective inhibition of the nearby MHDS does not alter defensive responses to conspecific aggressor demonstrating a double disso- ciation between these two medial hypothalamic defense systems (Silva et al. 2013). Like the MHDS, the medial hypothalamic reproductive system receives inputs from the MEA (although from a different sub-region to the one processing predatory cues) conveying pheromone signals from the AOS, and projects to motor output system centered in the PAGd (Canteras et al. 1994; 1995; Motta et al. 2009).

The overlap between the conspecific defense and reproductive and aggressive medial hypothalamic systems is intriguing. Recent insights about the relation between sex and aggressionregulating neurons in the $\mathrm{VMH}$ indicate that largely nonoverlapping sets of neurons in the VMHvl may mediate mounting and attack (Lin et al. 2011; Yang et al. 2013). However, how these populations relate to the cells mediating conspecific defensive responses remains to be determined. Likewise, a better understanding of the co-processing of conspecific defense and aggression in the medial hypothalamus is required to determine how animals select or switch behavioral strategies during agonistic encounters.

\section{The footshock fear circuit}

As discussed above (Box 1), painful stimuli are not considered to elicit innate defensive responses, but instead to serve as informative unconditioned stimuli that instruct associative learning to environmental cues. Because of the methodological advantages of studying conditioned responses in the laboratory, the neural circuits supporting footshock-induced conditioning have been extensively investigated (for reviews, see Herry and Johansen 2014; Tovote et al. 2015). This neural integration is mediated by a dedicated amygdala pathway (Box 1, Fig. 2C) that does not seem to overlap with conspecific or social fear processing structures (Gross and Canteras 2012).

Importantly, pain signals often accompany the encounter with other classes of threats such as aggressive conspecifics or predators. However, the integration of noxious stimuli in the predator and conspecific fear systems has thus far no been investigated. One possible source of cross talk between pain signals and predator and conspecific fear systems may originate from the parabrachial nucleus, a structure integrating visceroceptive pain and targeting both the CEA and the medial hypothalamic defensive circuit (Bernard and Besson 1990; Bester et al. 1997), but this remains speculation at this point.

\section{Internal states-emotional states}

The study of fear as an emotion in animals has been challenged because it remains difficult to test whether animals are experiencing a conscious feeling of emotion analogous to that of humans (Ledoux 2012, 2014). Nevertheless, specific criteria have recently been proposed for identifying the neural correlates of an internal state with emotion-like value (Anderson and Adolphs 2014). A brain structure mediating such an internal emotional state, first, should integrate signals from different sensory modalities including innate and conditioned stimuli; second, should be necessary and sufficient to drive a diverse set of environmentally appropriate defensive responses; and, third, its neural activity should be required to instruct a memory of the experience. The fulfillment of these criteria implies that a structure is not merely a relay station of a primary sensory input, nor an initiator of a specific motor response, but, instead, occupies an intermediate position giving rise to an internal state with an a possible human-like emotional value (Anderson and Adolphs 2014). A very limited number of studies have investigated the function of innate fear integration structures in this perspective. The few that have suggest that, at least in the case of predator fear, the medial hypothalamic defensive system may serve as a central processor of an internal emotional state. In the following section, we summarize these recent 
findings. In the future, similar studies need to be conducted to explore possible homologous structures mediating an internal state of fear induced by other types of threats such as social or nociceptive ones.

\section{MHDS, integration of diverse sensory stimuli}

A number of tract-tracing studies have shown that the MHDS receives projections from a wide range of sensory processing areas (Canteras 2002). For instance, the MHDS receives vomeronasal information from the medial amygdala (mainly targeting the $\mathrm{VMH})$, but also from the BMAp that, in turn, receives input from the BLA. The MHDS is therefore well positioned to integrate information from olfactory, insular, and prefrontal cortical areas. The MHDS also receives information about novelty and context from the hippocampus via inputs from the septum to AH (Canteras 2002). And finally the MHDS receives projections from the $\mathrm{PB}$, an important relay area of noxious information (Canteras 2002). The diversity of inputs to the MHDS makes it an ideal candidate structure able to respond to a wide variety of sensory information about environmental threats. Accordingly, loss-offunction studies confirm that selective impairment of VMHdm neurons not only reduces defensive responses to a predator (Silva et al. 2013) but also reduces tone fear conditioning and anxiety (Kunwar et al. 2015), as well as defensive responses to a context previously associated with a predator (Silva et al. 2016).

\section{MHDS, induction of multiple defensive behaviors}

Both loss- and gain-of-function studies indicate that the MHDS is able to support a variety of environmentally appropriate defensive behaviors and is not bound to a specific behavioral or physiological response. For example, blockade of the VMHdm or PMD impairs freezing, avoidance, escape, risk assessment, anxiety, and autonomic responses (Blanchard et al. 2003, 2005; Silva et al. 2013; Cheung et al. 2015; Kunwar et al. 2015), while optogenetic activation of the VMHdm induces flights, freezing, autonomic activation, and the interruption of ongoing behaviors (Lin et al. 2011; Kunwar et al. 2015; Wang et al. 2015). Interestingly, VMH activation seems to evoke defensive behaviors in a scalable fashion, with less intense stimulation inducing freezing and more intense stimulation evoking activity bursts (Kunwar et al. 2015). Different VMH outputs may regulate different defensive behaviors, with projections to the PAGd mediating freezing and projections to the AH mediating risk assessment and flight (Wang et al. 2015), although both outputs must presumably eventually reach the PAG to produce defensive responses. The VMH also activates sympathetic nervous system responses including pupil dilation, tachycardia, and hyperventilation (Satoh et al. 1999; Wang et al. 2015), which may be mediated by its direct projections to the rostral ventrolateral medulla (RVLM) (Lindberg et al. 2013) a structure harboring catecholaminergic neurons and capable of mediating sympathetic outflow (Burke et al. 2011).

\section{MHDS, role in memory formation}

Importantly, the MHDS is necessary and sufficient for mediating both innate and learned defensive responses. Lesions and pharmacological inhibition of the PMD and VMHdm reduce acute responses to a predator, but also inhibit defensive responses to the context where the predator was encountered at a later time point (Cezario et al. 2008; Do-Monte et al. 2008; Silva et al. 2013; Silva et al. 2016). Similarly, pharmacological activation of $\beta$-adrenergic receptors within this structure is sufficient to serve as an unconditioned stimulus to drive contextual fear learning (Pavesi et al. 2011) and optogenetic stimulation of VMHdm is sufficient to instruct learning in a conditioned place aversion test (Kunwar et al. 2015). Taken together, these results indicate that the
MHDS is necessary and sufficient for the encoding and recall of fear memory.

\section{Fear response output unit}

\section{Defensive responses in rodents}

When animals are exposed to a threat, they activate a range of immediate and delayed responses aimed at coping with it. Such responses are adapted to the type of threat and to the circumstances under which the threat is presented. For example, flight is preferred over freezing if an escape route is available and these responses show scalability depending on the proximity of the threat (Fanselow and Lester 1988; Blanchard and Blanchard 1990). In contrast, fear responses to ambiguous threat cues, like predator odor or open and bright spaces typically elicit risk assessment responses, including careful scanning of the environment in a crouched position (crouched sniffing) and attempts to approach the threatening stimulus by stretching the body (stretch postures) followed by rapid escapes to a shelter if available (Blanchard and Blanchard 1988). Moreover, fear responses tend to inhibit other types of ongoing motivated behaviors like feeding and mating (Blanchard and Blanchard 1988). This complex array of defensive behaviors, together with the endocrine and autonomic adjustments occurring upon threat exposure, is orchestrated by specific fear response output circuits.

\section{PAG: a common output for defense}

In their seminal study Hunsperger et al. discovered that fear responses elicited by stimulation of the amygdala or the hypothalamus could be reversed by PAG lesions, but not the other way around (Hunsperger et al. 1963). Since then, a growing body of evidence has accumulated pointing to the PAG as the final common path for all types of defensive responses. First, neuronal activation in the PAG has been observed upon exposure to a wide variety of threats, including live predator or predator odor (Cezario et al. 2008), aggressive conspecifics (Motta et al. 2009), loud ultrasound stimuli (Mongeau et al. 2003), and electrical footshock (Johansen et al. 2010). Second, impairment of PAG function diminishes the expression of defensive behaviors including freezing, risk assessment, flight, analgesia, and autonomical arousal (Hunsperger et al. 1963, Schenberg et al. 2014; Sukikara et al. 2006; Silva et al. 2013). Third, stimulation of the PAG is sufficient to induce defensive responses of various types, including freezing, escape, and jumping (Bandler and Shipley 1994; Schenberg et al. 2014).

The PAG is divided into rostro-caudal columns that have been proposed to control different behavioral outputs (Bittencourt et al. 2004). The dorsal columns of the PAG (PAGd) represent the main output structures of the medial hypothalamic defensive system (Canteras et al. 1994; Canteras 2002; Gross and Canteras 2012) as well as of the SC and IC (Canteras et al. 1992) and mediate active defensive responses to imminent threats like predators and aggressive conspecifics (Sukikara et al. 2006; Motta et al. 2009; Silva et al. 2013). Such active defensive strategies include escape, freezing associated with muscular tension, tachycardia, hypertension, hypervigilance, and hyperreactivity (Schenberg et al. 2014; Sukikara et al. 2006; Wang et al. 2015). The dorsal columns of the PAG project to downstream brain stem structures, including the cuneiform nucleus, periabducens region of the rostral dorsomedial pons, the locus coeruleus, and the ventromedial, ventrolateral, and dorsal medulla (Bandler and Shipley 1994). However, still little is known about how these diverse outputs may differentially contribute to the generation of the wide variety of PAGd-mediated defensive responses. 
In contrast, the ventral PAG columns (PAGvl) receive strong inputs from CEA and appear to mediate passive defensive responses associated with parasympathetic activation (bradycardia, hypotension, and hyporeactivity), antinociception, and vocalization (Fanselow 1991; Bandler and Shipley 1994; LeDoux 2003; Johansen et al. 2011), a defensive strategy typically observed in rodents exposed to neutral cues previously associated with footshock. The PAGvl seems to mediate these passive defensive responses though its downstream projections to the ventromedial and ventrolateral medulla and to the cerebellum (Vianna and Brandão 2003; Koutsikou et al. 2014; Tovote et al. 2016). However, here too, the precise contribution of each target structure to the different behavioral outcomes remains to be determined.

\section{Environment-appropriate fear responses}

A limited number of studies have examined how similar threat stimuli can elicit different defensive responses depending on the context. The CEA seems to contribute to this process as projections to cholinergic forebrain nuclei and PAGvl mediate the switch between active and passive fear responses, respectively (Gozzi et al. 2010). Nevertheless, how information about the environment, like the availability of an escape route, is integrated to switch to the most appropriate defensive strategy remains unclear. Mongeau et al. (2003) showed that mice display a tendency for active or passive defense to the same innate fearful stimulus depending on the levels of stress prior to exposure and that this is reflected in differential c-Fos activation patterns. In particular, mice performing active fear responses showed preferential recruitment of a cortical-amygdalo-striatal circuit, whereas mice showing passive defensive responses displayed higher levels of activation in the ventral lateral septum and periventricular zone of the hypothalamus. Moreover, in a recent study Tovote et al. (2016) showed that the same population of GABAergic neurons in the PAGvl is inhibited by long-range inhibitory CEA neurons promoting freezing responses and activated by flight promoting excitatory neurons located in the PAGd. This suggests that PAGvl GABAergic neurons may serve as a major integrator of different upstream inputs for the appropriate switch between active or passive defensive strategies.

\section{Fear memorization: how do innate fear circuits instruct memory formation?}

Exposure to a threat not only triggers acute responses aimed at immediate coping with the danger, but also brain plasticity that allows the subject to adapt its response to future encounters with similar threats. In this perspective, innate fear circuits must recruit both behavioral output structures and brain areas devoted to memory formation. A number of studies have investigated Pavlovian associative learning that accompany exposure to footshock and have nicely unraveled the circuitry, cell-type contribution, and cellular and molecular mechanisms at the basis of this process (the full description of which is beyond the aim of this review; Herry and Johansen 2014; Tovote et al. 2015).

In contrast, much less is known about the learning processes and plasticity mechanisms at the basis of the memorization of innate fear of more ethologically relevant threats such as predators or aggressive conspecifics. Fear memory upon exposure to these threats has been observed, because rodents show defensive responses to a context previously associated to predatory or social threats and loss-of-function studies have led to the identification of a core learning unit necessary for this memorization process. Unlike acute fear, fear memory seems to rely on this common pathway independently of the type of threat. It involves the hippocampus and amygdala as well as cortical circuits centered on the anterior cingulate, medial prefrontal, retrosplenial, and postrhinal areas (Ledoux 2000; Maren 2001, 2011). Corroborating this hypothesis, pharmacological inhibition or lesioning of these structures impairs memory encoding of fear of all types of threats while leaving acute responses unaffected. For example, impairment of BLA function prevents fear learning in animals exposed to footshock (Helmstetter and Bellgowan 1994), predators (Martinez et al. 2011), and aggressive conspecifics (Jasnow and Huhman 2001); similarly, inhibition of the ventral hippocampus impairs fear learning to footshock (Maren 1999), predators (Blanchard et al. 2005), and aggressive conspecifics (Markham et al. 2010).

On the other hand, several studies indicate that integration structures directly driving innate fear are also crucial to generate a memory of the aversive event. Even if the functional interactions of these circuits with the amygdalo-hippocampal-cortical learning unit are not fully understood, one possible model is that innate fear circuits for all types of threats convey threat signals to the higher learning unit where the association with contextual signals may take place (Fig. 2). This hypothesis is yet to be fully demonstrated, but a growing body of studies is providing functional and anatomical evidence for an interplay between the different innate fear circuits and structures devoted to memory formation.

For example, in the case of the predator fear system, both loss- and gain-of-function studies have demonstrated the causal implication of the MHDS in fear learning: Lesions or pharmacological inhibition of the PMD and of the VMHdm before predator exposure impairs fear responses to the environment where the predator was presented (Cezario et al. 2008; Do-Monte et al. 2008; Kunwar et al. 2015; Silva et al. 2016) and their activation is sufficient to induce conditioning (Pavesi et al. 2011; Kunwar et al. 2015). Communication from the MHDS to the cortico-hippocampal learning unit seems to occur through thalamic projections. Specifically, the PMD sends collaterals to MTN including the anteromedial thalamic nucleus (AM, Canteras et al. 2001) which, when blocked before predator exposure, impairs defensive responses to the context previously associated with a predator leaving acute responses to the predator unaffected (CarvalhoNetto et al. 2010; de Lima et al. 2016). The AM projects to the ACC, retrosplenial, entorhinal, perirhinal corteces, and the subiculum (Van Groen et al. 1999), areas implicated in contextual fear learning (Ledoux 2000; Maren 2001, 2011).

A second route of communication from the predator fear circuit to memory systems may stem from the PAGd. Pharmacological activation of PAGd is sufficient to induce defensive responses to the context where the stimulation occurred (Kincheski et al. 2012). The mnemonic effects of PAG stimulation may be mediated by PAG projections to PMD, as well as by direct projections to thalamic nuclei including intralaminar, laterodorsal, reuniens, suprageniculate, and subparafascicular thalamic nuclei (Kincheski et al. 2012). However, pharmacogenetic inhibition of dorsal PAG does not impair predator learning despite reducing acute fear responses (Silva et al. 2016), implying that at least for VMH, the PAG does not mediate the mnemonic effects of MHDS stimulation, but by a so far unknown route.

Similarly to predator fear, conspecific fear memory encoding requires the BLA, prefrontal cortex, and the ventral hippocampus (Markham et al. 2010; 2012). However, it is less clear how the conspecific fear circuit instructs the fear learning unit. Similar to the predator fear circuit, the dorsomedial PMD, a subregion of the PMD mediating acute conspecific fear (Motta et al. 2009), might contribute to instruct fear memory through projections to MTN that, in turn project to cortical and hippocampal structures, but this remains highly speculative.

Painful stimuli such as an electrical footshock also have the capability to instruct memory formation via a learning system 
relying on the amygdala, hippocampus, and prefrontal cortex (see "Box 1," "pain as an instructive threat stimulus," and "the footshock fear system") and a plethora of studies has investigated this memory process (for recent reviews, see Herry and Johansen 2014; Tovote et al. 2015). Interestingly, recent studies have started to investigate how neurons responding to innate fear stimuli interact with neurons mediating learned responses to a neutral cue. For instance, a recent study nicely showed that a specific neuronal population in the CEA mediating innate fear to predator odor inhibits learned freezing responses to a foot-shock associated cue. This finding indicates that this neuronal population in the CEA serves as a hierarchy generator between defensive responses that prioritizes innate fear over learned fear responses (Isosaka et al. 2015). In the same perspective another recent study showed that neurons in the BLA selectively mediate conditioned responses to a neutral stimulus by recruiting innate fear neurons to generate defensive responses (Gore et al. 2015).

It is important to bear in mind that many aspects of predator and social fear memory remain unknown. First, to our knowledge, no study has investigated the neuronal plasticity and molecular mechanisms underlying this form of memory. Second, the brain structures and cell types harboring these changes have yet to be identified. And, third, it remains unclear if fear memory following exposure of social and predatory threats is truly a pure associative type of learning, because also nonassociative components like generalized hyperarousal have been described (Fifield et al. 2015).

\section{Conclusions and future perspectives}

Here we aimed to summarize in a comprehensive manner how the brain processes threat signals to generate both acute and longterm innate fear responses. In particular, we were interested in framing together fear systems recruited by a vast variety of threats. We propose that it is conceptually useful to divide fear-processing structures in the brain in three fundamental functional units: a detection unit, an integration unit, and an output unit, which interact with a common memorization system. Moreover, we outline that the processing of acute fear resides in separate circuits at all functional levels depending on the type of threat, whereas they seem to recruit the same brain systems to instruct a memory of the fearful event.

Importantly, these different fear systems have only been investigated in separate studies, leaving unclear how they interact with each other. To address this issue, more comprehensive studies investigating the different fear systems in a unitary fashion will be required. Moreover, the interplay between the innate and learned fear systems remains poorly understood. For example, a recent study showed that CEA neurons mediating innate fear responses to predator odor can serve as a hierarchy generator prioritizing innate fear responses over learned ones (Isosaka et al. 2015)

Another important issue is that the investigation of the neural correlates of fear in rodents have classically been limited to the sensory-motor processing of defensive responses to a threat and only few studies have tried to uncover the brain circuits generating an "emotional state of fear" (Kunwar et al. 2015; Silva et al. 2016). Taking into consideration the translational potential of rodent studies to understand human physiology, this would be a crucial point as it would pave the way to understand how the circuits identified in the mouse relate to the brain correlates of human emotion of fear. In the future we should thus include these criteria in the study of the neural correlates of fear in rodents and aim beyond the classical sensory motor model of defensive responses.

Along these lines, a number of fMRI studies investigating the neural correlates of fear in human subjects have found that amyg- dalar activity is associated with fear states (LaBar et al. 1998). However, other fear systems identified in rodents are also related to fear states in humans. In an fMRI study in humans, Mobbs et al. (2007) showed that as a virtual predator approached the subjects, brain activity shifted from the ventromedial prefrontal cortex to the PAG. In addition, electrical stimulation at the level of the PAG and VMH in human subjects induced panic and the sensation of being chased, respectively (Amano et al. 1982; Wilent et al. 2010), suggesting that fear circuits may rely on similar structures as in rodents. Moreover, a recent study showed that patients with bilateral amygdala lesions developed panic attacks upon exposure to a $\mathrm{CO}_{2}$ inhalation test, which suggests that an alternative pathway mediates panic in humans (Feinstein et al. 2013). These findings indicate that the functional segregation of different kinds of fear may be conserved in humans, which is important to consider in the study of the human pathophysiology of fear.

Accordingly, particular attention should be paid to investigate how the different fear circuits described above may be dysregulated in fear-related pathological states like phobias, post-traumatic stress, and anxiety disorders. For example, it has been hypothesized that panic disorder resides in a dysregulation of the suffocation alarm system (Klein 1993; Preter and Klein 2008; 2014), but clear experimental evidence for this is lacking. In extension, it would also be interesting to assess how genetic predisposition for these pathological states might alter not only learned fear responses, but also innate fear responses, and whether an excessive innate fear response might predispose an individual for exaggerated learned fear responses.

Lastly, it is important to note that most of our knowledge about the functional dissociation of different brain circuits arises from older studies, in which brain function was inferred using a combination of anatomical tract-tracing studies, c-Fos-based functional mapping, lesions, and pharmacological inhibition. Although these studies provided fundamental insight in the function of fear circuits, they have major limitations such as temporal and cellular resolution. The advent of new tools for the investigation and manipulation of genetically defined populations of neurons such as optogenetics, chemogenetics, endoscopic calcium imaging, together with novel genetically encoded neuroanatomical tracing tools are likely to yield major breakthroughs in the field and will allow answering these and other open questions at better spatiotemporal resolution in future studies.

\section{Acknowledgments}

B.A.S. is a European Molecular Biology Organization (EMBO) long-term fellow (ALTF 1605-2014, Marie Curie Actions, LTFCOFUND2013, GA-2013-609409). The laboratory of C.T.G. is supported by EMBL and European Research Council (ERC) (ERC-2013-ADG 341139). J.G. is a MQ fellow and a National Association for Research on Schizophrenia and Depression (NARSAD) Independent Investigator. The laboratory of J.G. is supported by the ERC (ERC-2015-StG 678832), by the Swiss National Science Foundation, the National Competence Center for Research SYNAPSY, the SYNAPSIS Foundation, the Béatrice Ederer-Weber Stiftung, and the Alzheimer's Association.

\section{References}

Adolphs R. 2013. The biology of fear. Curr Biol 23: R79-R93.

Amano K, Tanikawa T, Kawamura H, Iseki H, Notani M, Kawabatake H, Shiwaku T, Suda T, Demura H, Kitamura K. 1982. Endorphins and pain relief. Further observations on electrical stimulation of the lateral part of the periaqueductal gray matter during rostral mesencephalic reticulotomy for pain relief. Appl. Neurophysiol. 45: 123-135.

Anderson DJ, Adolphs R. 2014. A framework for studying emotions across species. Cell 157: 187-200. 
Apfelbach R, Blanchard CD, Blanchard RJ, Hayes RA, McGregor IS. 2005. The effects of predator odors in mammalian prey species: a review of field and laboratory studies. Neurosci Biobehav Rev 29: 1123-1144.

Asede D, Bosch D, Lüthi A, Ferraguti F, Ehrlich I. 2015. Sensory inputs to intercalated cells provide fear-learning modulated inhibition to the basolateral amygdala. Neuron 86: 541-554.

Bandler R, Shipley MT. 1994. Columnar organization in the midbrain periaqueductal gray: modules for emotional expression? Trends Neurosci 17: 379-389.

Ben-Shaul Y, Katz LC, Mooney R, Dulac C. 2010. In vivo vomeronasal stimulation reveals sensory encoding of conspecific and allospecific cues by the mouse accessory olfactory bulb. Proc Natl Acad Sci 107: $5172-5177$.

Bernard JF, Besson JM. 1990. The spino(trigemino)pontoamygdaloid pathway: electrophysiological evidence for an involvement in pain processes. J Neurophysiol 63: 473-490.

Bester H, Besson JM, Bernard JF. 1997. Organization of efferent projections from the parabrachial area to the hypothalamus: a Phaseolus vulgaris-leucoagglutinin study in the rat. J Comp Neurol 383: 245-281.

Bienvenu TCM, Busti D, Micklem BR, Mansouri M, Magill PJ, Ferraguti F, Capogna M. 2015. Large intercalated neurons of amygdala relay noxious sensory information. J Neurosci 35: 2044-2057.

Bittencourt AS, Carobrez AP, Zamprogno LP, Tufik S, Schenberg LC. 2004 Organization of single components of defensive behaviors within distinct columns of periaqueductal gray matter of the rat: Role of $\mathrm{N}$-methyl-D-aspartic acid glutamate receptors. Neuroscience 125: 71-89.

Blanchard DC, Blanchard RJ. 1988. Ethoexperimental approaches to the biology of emotion. Annu Rev Psychol 39: 43-68.

Blanchard RJ, Blanchard DC. 1989. Attack and defense in rodents as ethoexperimental models for the study of emotion. Prog Neuropsychopharmacol Biol Psychiatry 13(Suppl): S3-S14.

Blanchard RJ, Blanchard DC. 1990. Anti-predator defense as models of animal fear and anxiety. In Fear and defence (ed. Brain PF, Parmigiani S, Blanchard RJ, Mainardi D), vol. 8, pp. 89-108. Harwood Academic, Amsterdam, Netherlands.

Blanchard RJ, Blanchard DC, Agullana R, Weiss SM. 1991. Twenty-two kHz alarm cries to presentation of a predator, by laboratory rats living in visible burrow systems. Physiol Behav 50: 967-972.

Blanchard DC, Li CI, Hubbard D, Markham CM, Yang M, Takahashi LK, Blanchard RJ. 2003. Dorsal premammillary nucleus differentially modulates defensive behaviors induced by different threat stimuli in rats. Neurosci Lett 345: $145-148$.

Blanchard DC, Canteras NS, Markham CM, Pentkowski NS, Blanchard RJ. 2005. Lesions of structures showing FOS expression to cat presentation effects on responsivity to a cat, cat odor, and nonpredator threat. Neurosci Biobehav Rev 29: 1243-1253.

Bolles RC, Fanselow MS. 1980. A perceptual-defensive-recuperative model of fear and pain. Behav Brain Sci 3: 291-323.

Brechbühl J, Klaey M, Broillet M-C. 2008. Grueneberg ganglion cells mediate alarm pheromone detection in mice. Science 321: 1092-1095.

Breer H, Fleischer J, Strotmann J. 2006. The sense of smell: multiple olfactory subsystems. Cell Mol Life Sci 63: 1465-1475.

Brunzell DH, Kim JJ. 2001. Fear conditioning to tone, but not to context, is attenuated by lesions of the insular cortex and posterior extension of the intralaminar complex in rats. Behav Neurosci 115: 365-375.

Burke PGR, Neale J, Korim WS, McMullan S, Goodchild AK. 2011. Patterning of somatosympathetic reflexes reveals nonuniform organization of presympathetic drive from C1 and non-C1 RVLM neurons. Am J Physiol Regul Integr Comp Physiol 301: R1112-R1122.

Canteras NS. 2002. The medial hypothalamic defensive system: hodological organization and functional implications. Pharmacol Biochem Behav 71: 481-491.

Canteras NS, Simerly RB, Swanson LW. 1992. Projections of the ventral premammillary nucleus. J Comp Neurol 324: 195-212.

Canteras NS, Simerly RB, Swanson LW. 1994. Organization of projections from the ventromedial nucleus of the hypothalamus: a Phaseolus vulgaris-leucoagglutinin study in the rat. J Comp Neurol 348: 41-79.

Canteras NS, Simerly RB, Swanson LW. 1995. Organization of projections from the medial nucleus of the amygdala: a PHAL study in the rat. $J$ Comp Neurol 360: 213-245.

Canteras NS, Chiavegatto S, Ribeiro do Valle LE, Swanson LW. 1997. Severe reduction of rat defensive behavior to a predator by discrete hypothalamic chemical lesions. Brain Res Bull 44: 297-305.

Canteras NS, Ribeiro-Barbosa ÉR, Comoli E. 2001. Tracing from the dorsal premammillary nucleus prosencephalic systems involved in the organization of innate fear responses. Neurosci Biobehav Rev 25: 661-668.

Carvalho-Netto EF, Martinez RCR, Baldo MVC, Canteras NS. 2010. Evidence for the thalamic targets of the medial hypothalamic defensive system mediating emotional memory to predatory threats. Neurobiol Learn Mem 93: 479-486.
Casanova JP, Contreras M, Moya EA, Torrealba F, Iturriaga R. 2013. Effect of insular cortex inactivation on autonomic and behavioral responses to acute hypoxia in conscious rats. Behav Brain Res 253: 60-67.

Cezario AF, Ribeiro-Barbosa ER, Baldo MVC, Canteras NS. 2008. Hypothalamic sites responding to predator threats - the role of the dorsal premammillary nucleus in unconditioned and conditioned antipredatory defensive behavior. Eur J Neurosci 28: 1003-1015.

Cheung CC, Krause WC, Edwards RH, Yang CF, Shah NM, Hnasko TS, Ingraham HA. 2015. Sex-dependent changes in metabolism and behavior, as well as reduced anxiety after eliminating ventromedial hypothalamus excitatory output. Mol Metab 4: 857-866.

Ciocchi S, Herry C, Grenier F, Wolff SBE, Letzkus JJ, Vlachos I, Ehrlich I, Sprengel R, Deisseroth K, Stadler MB, et al. 2010. Encoding of conditioned fear in central amygdala inhibitory circuits. Nature $\mathbf{4 6 8}$ : $277-282$.

Comoli E, Ribeiro-Barbosa ÉR, Canteras NS. 2000. Afferent connections of the dorsal premammillary nucleus. J Comp Neurol 423: 83-98.

Dean P, Mitchell IJ, Redgrave P. 1988. Responses resembling defensive behaviour produced by microinjection of glutamate into superior colliculus of rats. Neuroscience 24: 501-510.

Dean P, Redgrave P, Westby GWM. 1989. Event or emergency? Two response systems in the mammalian superior colliculus. Trends Neurosci 12: $137-147$

de Lima MA, Baldo MV, Canteras NS. 2016. A role for the anteromedial thalamic nucleus in the acquisition of contextual fear memory to predatory threats. Brain Struct Funct 1-17.

Di Scala G, Mana MJ, Jacobs WJ, Phillips AG. 1987. Evidence of Pavlovian conditioned fear following electrical stimulation of the periaqueductal grey in the rat. Physiol Behav 40: 55-63.

Do-Monte FHM, Canteras NS, Fernandes D, Assreuy J, Carobrez AP. 2008. New perspectives on $\beta$-adrenergic mediation of innate and learned fear responses to predator odor. J Neurosci 28: 13296-13302.

Dulac C, Torello AT. 2003. Molecular detection of pheromone signals in mammals: from genes to behaviour. Nat Rev Neurosci 4: 551-562.

Duvarci S, Popa D, Paré D. 2011. Central amygdala activity during fear conditioning. J Neurosci 31: 289-294.

Endres T, Fendt M. 2008. Inactivation of the lateral septum blocks fox odor-induced fear behavior. Neuroreport 19: 667-670.

Fanselow MS. 1990. Factors governing one-trial contextual conditioning. Anim Learn Behav 18: 264-270.

Fanselow MS. 1991. The midbrain periaqueductal gray as a coordinator of action in response to fear and anxiety functional behavior systems and fear. In Midbrain periaqueductal gray matter (ed. Depaulis A, Bandler R), Vol. 213, pp. 151-173. Springer, New York.

Fanselow MS. 1994. Neural organization of the defensive behavior system responsible for fear. Psychon Bull Rev 1: 429-438.

Fanselow MS, Lester LS. 1988. A functional behavioristic approach to aversively motivated behavior: predatory imminence as a determinant of the topography of defensive behavior. In Evolution and learning (ed. Bolles RC, Beecher MD), pp. 185-212. Erlbaum, Hillsdale, NJ.

Feinstein JS, Buzza C, Hurlemann R, Follmer RL, Dahdaleh NS, Coryell WH, Welsh MJ, Tranel D, Wemmie JA. 2013. Fear and panic in humans with bilateral amygdala damage. Nat Neurosci 16: 270-272.

Fendt M, Endres T, Apfelbach R. 2003. Temporary inactivation of the bed nucleus of the stria terminalis but not of the amygdala blocks freezing induced by trimethylthiazoline, a component of fox feces. J Neurosci 23: $23-28$.

Ferrero DM, Lemon JK, Fluegge D, Pashkovski SL, Korzan WJ, Datta SR, Spehr M, Fendt M, Liberles SD. 2011. Detection and avoidance of a carnivore odor by prey. Proc Natl Acad Sci 108: 11235-11240.

Fifield K, Hebert M, Williams K, Linehan V, Whiteman JD, Mac Callum P, Blundell J. 2015. Time-dependent effects of rapamycin on consolidation of predator stress-induced hyperarousal. Behav Brain Res 286: $104-111$.

Finley JCW, Katz DM. 1992. The central organization of carotid body afferent projections to the brainstem of the rat. Brain Res 572: 108-116.

Gore F, Schwartz EC, Brangers BC, Aladi S, Stujenske JM, Likhtik E, Russo MJ, Gordon JA, Salzman CD, Axel R. 2015. Neural representations of unconditioned stimuli in basolateral amygdala mediate innate and learned responses. Cell 162: 134-145.

Gozzi A, Jain A, Giovanelli A, Bertollini C, Crestan V, Schwarz AJ, Tsetsenis T, Ragozzino D, Gross CT, Bifone A. 2010. A neural switch for active and passive fear. Neuron 67: 656-666.

Gross CT, Canteras NS. 2012. The many paths to fear. Nat Rev Neurosci 13: 651-658.

Han S, Soleiman M, Soden M, Zweifel L, Palmiter RD. 2015. Elucidating an affective pain circuit that creates a threat memory. Cell 162: 363-374.

Helmstetter FJ, Bellgowan PS. 1994. Effects of muscimol applied to the basolateral amygdala on acquisition and expression of contextual fear conditioning in rats. Behav Neurosci 108: 1005-1009.

Herry C, Johansen JP. 2014. Encoding of fear learning and memory in distributed neuronal circuits. Nat Neurosci 17: 1644-1654. 
Hopkins DA, Holstege G. 1978. Amygdaloid projections to the mesencephalon, pons and medulla oblongata in the cat. Exp Brain Res 32: 529-547.

Hunsperger RW. 1963. Comportements affectifs provoqués par la stimulation électrique du tronc cérébral et du cerveau antérieur. $J$ Physiol (Paris) 55: 45-97.

Isogai Y, Si S, Pont-Lezica L, Tan T, Kapoor V, Murthy VN, Dulac C. 2011. Molecular organization of vomeronasal chemoreception. Nature 478: 241-245.

Isosaka T, Matsuo T, Yamaguchi T, Funabiki K, Nakanishi S, Kobayakawa R, Kobayakawa K. 2015. Htr2a-expressing cells in the central amygdala control the hierarchy between innate and learned fear. Cell 163: 1153-1164.

Jasnow AM, Huhman KL. 2001. Activation of GABAA receptors in the amygdala blocks the acquisition and expression of conditioned defeat in Syrian hamsters. Brain Res 920: $142-150$.

Johansen JP, Tarpley JW, LeDoux JE, Blair HT. 2010. Neural substrates for expectation-modulated fear learning in the amygdala and periaqueductal gray. Nat Neurosci 13: 979-986.

Johansen JP, Cain CK, Ostroff LE, Ledoux JE. 2011. Molecular mechanisms of fear learning and memory. Cell 147: 509-524.

Keay KA, Redgrave P, Dean P. 1988. Cardiovascular and respiratory changes elicited by stimulation of rat superior colliculus. Brain Res Bull 20: $13-26$.

Keifer OP, Hurt RC, Ressler KJ, Marvar PJ. 2015. The Physiology of Fear: Reconceptualizing the Role of the Central Amygdala in Fear Learning. Physiology (Bethesda) 30: 389-401.

Kiernan MJ, Westbrook RF, Cranney J. 1995. Immediate shock, passive avoidance, and potentiated startle: Implications for the unconditioned response to shock. Anim Learn Behav 23: 22-30.

Kim EJ, Horovitz O, Pellman BA, Tan LM, Li Q, Richter-Levin G, Kim JJ. 2013. Dorsal periaqueductal gray-amygdala pathway conveys both innate and learned fear responses in rats. Proc Natl Acad Sci 110: 14795-14800.

Kincheski GC, Mota-Ortiz SR, Pavesi E, Canteras NS, Carobrez AP. 2012. The dorsolateral periaqueductal gray and its role in mediating fear learning to life threatening events. PLoS One 7: e50361.

Klein DF. 1993. False suffocation alarms, spontaneous panics, and related conditions. An integrative hypothesis. Arch Gen Psychiatry 50: 306-317.

Kobayakawa K, Kobayakawa R, Matsumoto H, Oka Y, Imai T, Ikawa M, Okabe M, Ikeda T, Itohara S, Kikusui T, et al. 2007. Innate versus learned odour processing in the mouse olfactory bulb. Nature 450: 503-508.

Kollack-Walker S, Newman SW. 1995. Mating and agonistic behavior produce different patterns of Fos immunolabeling in the male Syrian hamster brain. Neuroscience 66: 721-736.

Kollack-Walker S, Don C, Watson SJ, Akil H. 1999. Differential expression of c-fos mRNA within neurocircuits of male hamsters exposed to acute or chronic defeat. J Neuroendocrinol 11: 547-559.

Kondoh K, Lu Z, Ye X, Olson DP, Lowell BB, Buck LB. 2016. A specific area of olfactory cortex involved in stress hormone responses to predator odours. Nature 532: 103-106.

Koutsikou S, Crook JJ, Earl EV, Leith JL, Watson TC, Lumb BM, Apps R. 2014. Neural substrates underlying fear-evoked freezing: the periaqueductal grey-cerebellar link. J Physiol 592: 2197-2213.

Kramer JM, Nolan PC, Waldrop TG. 1999. In vitro responses of neurons in the periaqueductal gray to hypoxia and hypercapnia. Brain Res 835: 197-203.

Kunwar PS, Zelikowsky M, Remedios R, Cai H, Yilmaz M, Meister M, Anderson DJ. 2015. Ventromedial hypothalamic neurons control a defensive emotion state. Elife $\mathbf{4}$.

LaBar KS, Gatenby JC, Gore JC, LeDoux JE, Phelps EA. 1998. Human amygdala activation during conditioned fear acquisition and extinction: a mixed-trial fMRI study. Neuron 20: 937-945.

Landeira-Fernandez J, DeCola JP, Kim JJ, Fanselow MS. 2006. Immediate shock deficit in fear conditioning: effects of shock manipulations. Behav Neurosci 120: 873-879.

Lanuza E, Moncho-Bogani J, LeDoux JE. 2008. Unconditioned stimulus pathways to the amygdala: effects of lesions of the posterior intralaminar thalamus on foot-shock-induced c-Fos expression in the subdivisions of the lateral amygdala. Neuroscience 155: 959-968.

LeDoux JE, Iwata J, Cicchetti P, Reis DJ. 1988. Different projections of the central amygdaloid nucleus mediate autonomic and behavioral correlates of conditioned fear. J Neurosci 8: 2517-2529.

Ledoux JE. 2000. Emotion circuits in the brain. Annu Rev Neurosci 23: $155-184$.

LeDoux J. 2003. The emotional brain, fear, and the amygdala. Cell Mol Neurobiol 23: 727-738.

LeDoux J. 2012. Rethinking the emotional brain. Neuron 73: 653-676.

Ledoux JE. 2014. Coming to terms with fear. Proc Natl Acad Sci 111: $2871-2878$.
Li C-I, Maglinao TL, Takahashi LK. 2004. Medial amygdala modulation of predator odor-induced unconditioned fear in the rat. Behav Neurosci 118: $324-332$.

Liang F, Xiong XR, Zingg B, Ji XY, Zhang LI, Tao HW. 2015. Sensory cortical control of a visually induced arrest behavior via corticotectal projections. Neuron 86: 755-767.

Lin D, Boyle MP, Dollar P, Lee H, Lein ES, Perona P, Anderson DJ. 2011. Functional identification of an aggression locus in the mouse hypothalamus. Nature 470: $221-226$.

Lindberg D, Chen P, Li C. 2013. Conditional viral tracing reveals that steroidogenic factor 1-positive neurons of the dorsomedial subdivision of the ventromedial hypothalamus project to autonomic centers of the hypothalamus and hindbrain. J Comp Neurol 521: 3167-3190.

Lipp HP, Hunsperger RW. 1978. Threat, attack and flight elicited by electrical stimulation of the ventromedial hypothalamus of the marmoset monkey Callithrix jacchus. Brain Behav Evol 15: 260-293.

Litvin Y, Blanchard DC, Blanchard RJ. 2007. Rat 22kHz ultrasonic vocalizations as alarm cries. Behav Brain Res 182: 166-172.

Loewy AD, Burton H. 1978. Nuclei of the solitary tract: efferent projections to the lower brain stem and spinal cord of the cat. J Comp Neurol 181: 421-449.

Maren S. 1999. Neurotoxic or electrolytic lesions of the ventral subiculum produce deficits in the acquisition and expression of Pavlovian fear conditioning in rats. Behav Neurosci 113: 283-290.

Maren S. 2001. Neurobiology of Pavlovian fear conditioning. Annu Rev Neurosci 24: 897-931.

Maren S. 2011. Seeking a spotless mind: extinction, deconsolidation, and erasure of fear memory. Neuron 70: $830-845$.

Markham CM, Taylor SL, Huhman KL. 2010. Role of amygdala and hippocampus in the neural circuit subserving conditioned defeat in Syrian hamsters. Learn Mem 17: 109-116.

Markham CM, Luckett CA, Huhman KL. 2012. The medial prefrontal cortex is both necessary and sufficient for the acquisition of conditioned defeat. Neuropharmacology 62: 933-939.

Martinez RC, Carvalho-Netto EF, Ribeiro-Barbosa ÉR, Baldo MVC, Canteras NS. 2011. Amygdalar roles during exposure to a live predator and to a predator-associated context. Neuroscience 172: 314-328.

Matsumoto H, Kobayakawa K, Kobayakawa R, Tashiro T, Mori K, Sakano H, Mori K. 2010. Spatial arrangement of glomerular molecular-feature clusters in the odorant-receptor class domains of the mouse olfactory bulb. J Neurophysiol 103: 3490-3500.

Meredith M. 1991. Sensory processing in the main and accessory olfactory systems: comparisons and contrasts. J Steroid Biochem Mol Biol 39: 601-614.

Miyamichi K, Amat F, Moussavi F, Wang C, Wickersham I, Wall NR, Taniguchi H, Tasic B, Huang ZJ, He Z, et al. 2011. Cortical representations of olfactory input by trans-synaptic tracing. Nature 472: $191-196$.

Mobbs D, Petrovic P, Marchant JL, Hassabis D, Weiskopf N, Seymour B, Dolan RJ, Frith CD. 2007. When fear is near: threat imminence elicits prefrontal-periaqueductal gray shifts in humans. Science 317: 1079-1083.

Mongeau R, Miller GA, Chiang E, Anderson DJ. 2003. Neural correlates of competing fear behaviors evoked by an innately aversive stimulus. $J$ Neurosci 23: 3855-3868.

Motta SC, Goto M, Gouveia FV, Baldo MVC, Canteras NS, Swanson LW. 2009. Dissecting the brain's fear system reveals the hypothalamus is critical for responding in subordinate conspecific intruders. Proc Natl Acad Sci 106: $4870-4875$.

Neugebauer V, Li W. 2002. Processing of nociceptive mechanical and thermal information in central amygdala neurons with knee-joint input. J Neurophysiol 87: 103-112.

Panksepp J. 1989. The neurobiology of emotions: of animal brains and human feelings. In Handbook of social psychophysiology. Wiley handbooks of psychophysiology (ed. Wagner H, Manstead A), pp. 5-26. John Wiley \& Sons, Oxford, England.

Papes F, Logan DW, Stowers L. 2010. The vomeronasal organ mediates interspecies defensive behaviors through detection of protein pheromone homologs. Cell 141: 692-703.

Paton JFR, Deuchars J, Li YW, Kasparov S. 2001. Properties of solitary tract neurones responding to peripheral arterial chemoreceptors. Neuroscience 105: 231-248.

Pavesi E, Canteras NS, Carobrez AP. 2011. Acquisition of Pavlovian fear conditioning using $\beta$-adrenoceptor activation of the dorsal premammillary nucleus as an unconditioned stimulus to mimic live predator-threat exposure. Neuropsychopharmacology 36: 926-939.

Pérez-Gómez A, Bleymehl K, Stein B, Pyrski M, Birnbaumer L, Munger SD, Leinders-Zufall T, Zufall F, Chamero P. 2015. Innate predator odor aversion driven by parallel olfactory subsystems that converge in the ventromedial hypothalamus. Curr Biol 25: 1340-1346. 
Preter M, Klein DF. 2008. Panic, suffocation false alarms, separation anxiety and endogenous opioids. Prog Neuropsychopharmacol Biol Psychiatry 32: $603-612$.

Preter M, Klein DF. 2014. Lifelong opioidergic vulnerability through early life separation: a recent extension of the false suffocation alarm theory of panic disorder. Neurosci Biobehav Rev 46: 345-351.

Ricardo JA, Tongju Koh E. 1978. Anatomical evidence of direct projections from the nucleus of the solitary tract to the hypothalamus, amygdala, and other forebrain structures in the rat. Brain Res 153: 1-26.

Rodrigues SM, Schafe GE, LeDoux JE. 2004. Molecular mechanisms underlying emotional learning and memory in the lateral amygdala. Neuron 44: 75-91.

Root CM, Denny CA, Hen R, Axel R. 2014. The participation of cortical amygdala in innate, odour-driven behaviour. Nature 515: 269-273.

Rosen JB, Asok A, Chakraborty T. 2015. The smell of fear: innate threat of 2,5-dihydro-2,4,5-trimethylthiazoline, a single molecule component of a predator odor. Front Neurosci 9: 292.

Sahibzada N, Dean P, Redgrave P. 1986. Movements resembling orientation or avoidance elicited by electrical stimulation of the superior colliculus in rats. J Neurosci 6: 723-733.

Sato M, Ito M, Nagase M, Sugimura YK, Takahashi Y, Watabe AM, Kato F. 2015. The lateral parabrachial nucleus is actively involved in the acquisition of fear memory in mice. Mol Brain 8: 22.

Satoh N, Ogawa Y, Katsuura G, Numata Y, Tsuji T, Hayase M, Ebihara K, Masuzaki H, Hosoda K, Yoshimasa Y, et al. 1999. Sympathetic activation of leptin via the ventromedial hypothalamus: leptin-induced increase in catecholamine secretion. Diabetes 48: $1787-1793$.

Schenberg LC, Costa MB, Borges PCL, Castro MFS. 1990. Logistic analysis of the defense reaction induced by electrical stimulation of the rat mesencephalic tectum. Neurosci Biobehav Rev 14: 473-479.

Schenberg LC, Schimitel FG, Armini Rde S, Bernabé CS, Rosa CA, Tufik S, Müller CJT, Quintino-dos-Santos JW. 2014. Translational approach to studying panic disorder in rats: hits and misses. Neurosci Biobehav Rev 46: $472-496$.

Schimitel FG, de Almeida GM, Pitol DN, Armini RS, Tufik S, Schenberg LC. 2012. Evidence of a suffocation alarm system within the periaqueductal gray matter of the rat. Neuroscience 200: 59-73.

Shang C, Liu Z, Chen Z, Shi Y, Wang Q, Liu S, Li D, Cao P. 2015. A parvalbumin-positive excitatory visual pathway to trigger fear responses in mice. Science 348: 1472-1477.

Silva BA, Mattucci C, Krzywkowski P, Murana E, Illarionova A, Grinevich V, Canteras NS, Ragozzino D, Gross CT. 2013. Independent hypothalamic circuits for social and predator fear. Nat Neurosci 16: 1731-1733.

Silva BA, Mattucci C, Krzywkowski P, Cuozzo R, Carbonari L, Gross CT. 2016. The ventromedial hypothalamus mediates predator fear memory. Eur J Neurosci. 43(11): 1431-1439.

Sorge RE, Martin LJ, Isbester KA, Sotocinal SG, Rosen S, Tuttle AH, Wieskopf JS, Acland EL, Dokova A, Kadoura B, et al. 2014. Olfactory exposure to males, including men, causes stress and related analgesia in rodents. Nat Methods 11: 629-632.

Stowers L, Kuo TH. 2015. Mammalian pheromones: emerging properties and mechanisms of detection. Curr Opin Neurobiol 34: 103-109.

Stowers L, Logan DW. 2010. Olfactory mechanisms of stereotyped behavior: on the scent of specialized circuits. Curr Opin Neurobiol 20: $274-280$.

Sudré ECM, de Barros MR, Sudré GN, Schenberg LC. 1993. Thresholds of electrically induced defence reaction of the rat: short- and long-term adaptation mechanisms. Behav Brain Res 58: 141-154.
Sugimura YK, Takahashi Y, Watabe AM, Kato F. 2016. Synaptic and network consequences of monosynaptic nociceptive inputs of parabrachial nucleus origin in the central amygdala. J Neurophysiol 115: 2721-2739.

Sukikara MH, Mota-Ortiz SR, Baldo MV, Felício LF, Canteras NS. 2006. A role for the periaqueductal gray in switching adaptive behavioral responses. J Neurosci 26: 2583-2589.

Takahashi LK. 2014. Olfactory systems and neural circuits that modulate predator odor fear. Front Behav Neurosci 8: 72.

Tovote P, Fadok JP, Luthi A. 2015. Neuronal circuits for fear and anxiety. Nat Rev Neurosci 16: 317-331.

Tovote P, Esposito MS, Botta P, Chaudun F, Fadok JP, Markovic M, Wolff SBE, Ramakrishnan C, Fenno L, Deisseroth K, et al. 2016. Modbrain circuits for defensive behavior. Nature 534: 206-212.

Van Groen T, Kadish I, Wyss JM. 1999. Efferent connections of the anteromedial nucleus of the thalamus of the rat. Brain Res Rev 30: 1-26.

Vianna DML, Brandão ML. 2003. Anatomical connections of the periaqueductal gray: specific neural substrates for different kinds of fear. Braz J Med Biol Res 36: 557-566.

Walker DL, Toufexis DJ, Davis M. 2003. Role of the bed nucleus of the stria terminalis versus the amygdala in fear, stress, and anxiety. Eur J Pharmacol 463: 199-216.

Wallace DJ, Greenberg DS, Sawinski J, Rulla S, Notaro G, Kerr JND. 2013. Rats maintain an overhead binocular field at the expense of constant fusion. Nature 498: 65-69.

Wang L, Chen I, Lin D. 2015. Collateral pathways from the ventromedial hypothalamus mediate defensive behaviors. Neuron 85: $1344-1358$.

Wei P, Liu N, Zhang Z, Liu X, Tang Y, He X, Wu B, Zhou Z, Liu Y, Li J, et al. 2015. Processing of visually evoked innate fear by a non-canonical thalamic pathway. Nat Commun 6: 6756.

Wilensky AE, Schafe GE, Kristensen MP, LeDoux JE. 2006. Rethinking the fear circuit: the central nucleus of the amygdala is required for the acquisition, consolidation, and expression of Pavlovian fear conditioning. J Neurosci 26: $12387-12396$.

Wilent WB, Oh MY, Buetefisch CM, Bailes JE, Cantella D, Angle C, Whiting DM. 2010. Induction of panic attack by stimulation of the ventromedial hypothalamus. J Neurosurg 112: 1295-1298.

Xiong XR, Liang F, Zingg B, Ji X, Ibrahim LA, Tao HW, Zhang LI. 2015. Auditory cortex controls sound-driven innate defense behaviour through corticofugal projections to inferior colliculus. Nat Commun 6: 7224 .

Yang CF, Chiang MC, Gray DC, Prabhakaran M, Alvarado M, Juntti SA, Unger EK, Wells JA, Shah NM. 2013. Sexually dimorphic neurons in the ventromedial hypothalamus govern mating in both sexes and aggression in males. Cell 153: 896-909.

Yang H, Yang J, Xi W, Hao S, Luo B, He X, Zhu L, Lou H, Yu Y, Xu F, et al. 2016. Laterodorsal tegmentum interneuron subtypes oppositely regulate olfactory cue induced innate fear. Nat Neurosci 19: $283-289$

Yilmaz M, Meister M. 2013. Rapid innate defensive responses of mice to looming visual stimuli. Curr Biol 23: 2011-2015.

Zhao X, Liu M, Cang J. 2014. Visual cortex modulates the magnitude but not the selectivity of looming-evoked responses in the superior colliculus of awake mice. Neuron 84: 202-213.

Received April 28, 2016; accepted in revised form July 19, 2016. 


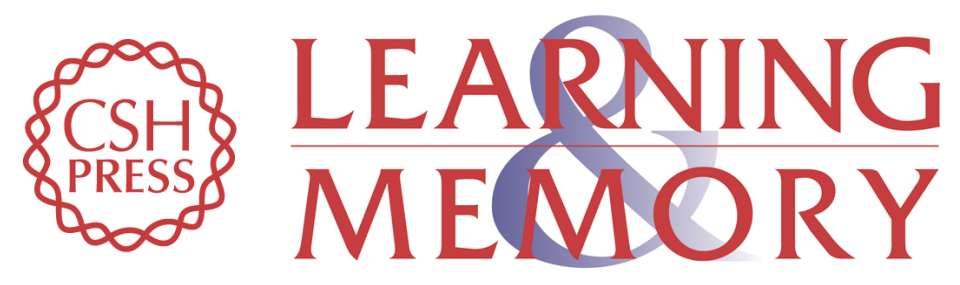

\section{The neural circuits of innate fear: detection, integration, action, and memorization}

Bianca A. Silva, Cornelius T. Gross and Johannes Gräff

Learn. Mem. 2016, 23:

Access the most recent version at doi:10.1101/Im.042812.116

References This article cites 143 articles, 19 of which can be accessed free at: http://learnmem.cshlp.org/content/23/10/544.full.html\#ref-list-1

Creative This article, published in Learning \& Memory, is available under a Creative Commons Commons License (Attribution 4.0 International), as described at

License http://creativecommons.org/licenses/by/4.0/.

Email Alerting Receive free email alerts when new articles cite this article - sign up in the box at the Service top right corner of the article or click here. 